\section{Coping Patterns in a Mother of a Child with Multiple Congenital Anomalies: A Case Study}

\section{Abstract}

Objective: To study the coping pattern of a mother of a child with multiple congenital anomalies (MCAs) based on interview data.

Methods: The mother of a child born at Tohoku University Hospital, Japan, who was diagnosed with MCAs at 3 days of age and subsequently underwent surgery at 7 months, was asked to be interviewed. She answered semi structured interviews at the hospital when the child was two years old and again when the child was five years old. Psychological assessment with the State-Trait Anxiety Inventory (STAI) and the Self-rating Depression Scale (SDS) was conducted before each interview.

Results: Psychological assessment showed that the mother had high levels of anxiety and depression when the child was two and when the child was five years old. The interview data showed that when the mother first learned that her baby had MCAs, her initial reaction was (1) shock. She then felt (2) Absent-minded. (3) Responsibility to take care of her child. (4) Depression, (5) Defense against acceptance of child's disease as it is. The mother had this sequence of thoughts and emotions between the times of diagnosis of MCAs up through the time of surgery. In the first stage of coping, the mother showed defense against learning as much as possible about her child's disease and MCAs. In the second stage of coping, the mother reported (when the child was five years old) that she felt that she had some control over her child's situation. The mother started to accept her child's disease as she as possible and learned what would be happened to her child.

Conclusion: The mother of the child with MCAs was in a severe psychological condition over at least five years since diagnosis. In order to alleviate the psychological stress on mothers of a child with MCAs or other congenital disease, it is useful to educate the mother so that she can understand her child's disease. However, it is difficult for parents without medical knowledge to understand a complicated disease such as MCAs. Providers need more training to educate parents with MCAs.

Keywords: Child with multiple congenital anomalies; Mother's coping style; Pediatric surgery; Trauma psychology; Structured interview

Received: April 10, 2017; Accepted: April 14, 2017; Published: April 21, 2017

\author{
Junko Okuyama ${ }^{1,2}$, \\ Shunichi Funakoshi ${ }^{2,3}$, \\ Shintaro Amae", \\ Takamichi Kamiyama ${ }^{5}$, \\ Takashi Ueno ${ }^{6}$ and \\ Yutaka Hayashi $^{7}$
}
1 Department of Psychiatry, Tohoku University Graduate School of Medicine, Japan
2 Miyagi Psychiatric Center, Japan
3 Department of Community Psychiatric Medicine, Tohoku University Graduate School of Medicine, Japan
4 Sunlight Welfare Meeting Echo Ryouikuen, Japan
5 Division of Pediatric Surgery, Iwaki Kyoritsu General Hospital, Japan
6 Division of Clinical Psychology, Department of Human Development and Disabilities, Tohoku University, Graduate School of Education, Japan
7 Miyagi Children's Hospital, Japan

\section{Corresponding author: Junko Okuyama}

Đ junko.okuyama@med.tohoku.ac.jp

MD, Department of Psychiatry, Tohoku University Graduate School of Medicine, Miyagi Psychiatric Center, Aza-yama, Tekurada, Natoricity, 981-1231, Japan.

Tel: +81223842236

Fax: +81223849100

Citation: Okuyama J, Funakoshi S, Amae S, et al. Coping Patterns in a Mother of a Child with Multiple Congenital Anomalies: A Case Study. J Intensive \& Crit Care 2017, 3:2.

\section{Introduction}

The presence of illness or disability in a child has long been recognized as a source of stress to families [1]. The research literature includes numerous studies indicating increased stress or psychological problems in families of children with various acute or chronic illnesses such as asthma, cancer, heart disease and diabetes [2-4]. In addition, mothers of a child with a disability experience psychosocial problems later than the fathers $[5,6]$. In families with a child with multiple congenital anomalies (MCAs), relatively little information on the stress of families, family functioning and coping patterns is available, which is surprising given the relatively high prevalence of MCAs.

Biliary atresia (BA) is the most common congenital hepatobiliary disorder that requires surgical treatment in infants, representing 
about $50 \%$ of all neonatal cholestatic jaundice cases [7-9]. Cardiovascular, splenic, and intestinal malformations are anomalies associated with BA. As described by Amae et al. [10], anorectal and urogenital malformations rarely accompany BA. Several studies have indicated that the presence of rare and multiple congenital anomalies in a child are associated with greater parenting stress (NOTE: Please cite several references). However, there has been no research on how families of children with these conditions deal with this stress. The results of such research may be helpful in developing specific support programs and services for these families.

\section{Biliary Atresia}

Biliary atresia (BA) is a rare congenital disease affecting infants. When an infant is diagnosed with this disease, the family must learn to cope with the surgery and surgical outcome. As the infant becomes older, the child must learn to cope with the surgical outcome. Cardiovascular, splenic and intestinal malformations are anomalies associated with BA. However, it is very rare that anorectal and urogenital malformations accompany BA [10]. Because of the rarity of this condition, there is a paucity of information available to families of an infant with BA with anorectal and urogenital malformations and to the health care providers who care for them.

Biliary atresia (BA) is the most common hepatobiliary disorder requiring surgical treatment in infants, representing about $50 \%$ of all neonatal cholestatic jaundice cases [7-9]. Kasai's portoenterostomy is the only surgical option in patients with BA in which the patients survive with their own liver. The long-term outcome of this surgery is closely related to the timing of the procedure and to the experience of the center. However, even if the surgery is performed under optimal conditions, stable liver function is not guaranteed. The majority of patients with BA eventually require liver transplantation, making them the largest group of pediatric organ recipients. Thus, surgery in infants with BA treats only the symptoms and does not treat the cause of the disease [11].

\section{Coping Patterns}

Severe MCAs such as anorectal or urogenital malformation may accompany $B A$, and this disease has long-lasting effects on the parents of a child with BA. To understand their life situation, it is important to know how they cope with the aftermath of the disease and treatment. Coping refers to the process that is activated when stress is perceived, intervening between stress and the observed outcome, and is aimed at regulating emotional distress and eliminating the stress $[12,13]$. To attain this goal, coping strategies operate to reduce or make tolerable the internal and external demands that are created by the stressful situation [12]. Thus, in addition to variables that affect the outcome of the coping process such as the type of stress, the situational context and personal characteristics, coping strategies play a significant role in the outcome of the coping process. (NOTE: Can you explain further what you would like to say in the underlined phrase?) We will investigate how the coping style that parent select, and look for what coping style is good for the parent's psychological status.

\section{Qualitative Approach}

The aim of our study was to give a comprehensive description of what it is like for parents to raise a child with MCAs. We used a qualitative research strategy because it matches well with the specific character of the problem under study, i.e., the complexity of the human experience. A qualitative approach considers the complexity and richness of human reality and tries to describe this complexity in the most penetrating way. This research method has been used to study parents of cancer survivors from the parent's own frame of reference [14-16]. Qualitative analysis uses language as the main mode of obtaining and processing data and results are provided by textual analysis.

The present study first explores the impact of MCAs in a child on the child's mother, followed by a description of the mother's way of coping with it.

\section{Methods}

\section{Subject}

We interviewed and assessed the mother of a girl with BA who also suffered from anorectal agenesis without a fistula and urogenital malformation. The details of the child's malformation and at the age of 7 months, the child underwent surgery, the details of which are shown in the case report [10]. The outcome of patients with these severe anomalies is poor, but she has survived without undergoing liver and/or renal transplantation for more than 5 years. Careful treatment plans for each anomaly in addition to treatments for preventing cholangitis and urinary tract infection are indispensable for managing these anomalies [10].

\section{Psychological measures}

The mental health and psychological functioning of the mother were assessed multimodally as described in detail elsewhere [1719]. To assess the psychological functioning of the mother, we administered the SDS (Self-rating Depression Scale) [20] and STAI (State-Trait Anxiety Inventory) [21] Japanese version (Sankyobo Corp., Kyoto, Japan) to the mother.

Spielberger [20] originally developed the STAI based on the characteristic-state model of anxiety. Nakazato et al. [22] established a Japanese version of the STAI, and studied its reliability and validity. The STAI is composed of two parts. The STAI-I is used to evaluate the state of anxiety, and the maximum score is 80 . Scores of 41 or less indicate normalcy, while scores of 42-50 imply a clinically significant state of anxiety. Furthermore, scores of over 50 indicate an extremely high level of anxiety (neurosis level). The STAI-II is used to evaluate characteristic anxiety, and the maximum score is 80 . Scores on the STAI-II of 44 or less represent normalcy, while scores of 45-54 indicate clinically significant characteristic anxiety. Scores of 55 or higher indicate extremely severe characteristic anxiety (neurosis level).

The SDS was originally developed by Zung [21] and the reliability and validity of the Japanese version have been confirmed in Japanese subjects [23]. The maximum score on the SDS is 80 points, and the average score among control subjects, subjects with neurosis, and subjects with depression was $35(S D=12)$, 
$49(S D=10)$ and $60(S D=7)$, respectively (Sankyobo Corp., Kyoto, Japan).

\section{Interviews}

This qualitative descriptive case study was undertaken to explore the process of a mother's coping with her child with MCAs. The research question addressed in this case study was, "What is the process of a mother's coping to the caring of her child with MCAs. Tape-recorded, unstructured interviews lasting 60 minutes were conducted with the mother of a 2 year old Japanese female child with biliary atresia with associated anorectal and urogenital malformations. Figure 1 shows the questions that the interviewer used as a guide to perform the unstructured interviews with the mother. A total of three interviews were conducted with the mother.

We interviewed and performed psychological assessment of the mother when the child was two years old and when the child was five years old. Interviews were conducted in the hospital. The interviews were transcribed verbatim. The data were analyzed using the grounded theory [24]. The central theme that emerged was the mother's ability to adapt to the child's disorder and continue caring for the child. Factors that made this adaptation possible were identified. We reviewed relevant literature on congenital malformation in children to compare and contrast the emerging concepts from this study and their relationships with the findings of previous studies. These emerging concepts were discussed with the mother and were modified until the investigator, informants and a colleague found them credible.

\section{Ethics}

This study was approved by the Ethics Committee of Tohoku University Hospital. The purpose of the study was explained in detail to the mother and father of the child with MCAs. Informed consent for the mother to participate in this study was obtained from the mother and father of the child with BA.

\section{Results}

\section{Psychological measures}

Before each interview, we administered the STAI, which is a self-assessment psychological measure of anxiety, and the SDS, which is a self-assessment psychological measure of depression.

The results are shown in Table 1 . The psychological measures showed that the mother had anxiety and depression for a long period of time (when the child was 2 and 5 years old).

\section{Interviews}

\section{Impact of MCAs in a child on the mother}

When the child was 2 years old, the mother described the impact of the child's diagnosis on her mind during the interval between the births of the child up to the time of this interview.

The diagnosis of congenital disease in an infant is usually unexpected by family members and the family is suddenly notified of the child's disease. The mother described shock when she learned about the significance of the disease. She said, "Just after the delivery, the nurse said, 'A cheerful girl was born. Please kiss this baby.' and showed my baby to me. I believed that a healthy baby had been born, but only three days later, the baby was admitted to the hospital. My shock was great..." "I was surprised to hear from doctors that only three children with the same MCAs as those in my child had been reported throughout the world in the literature." Surgery was performed when the child was 7 months old. The mother reported feeling absent-minded when the child was taken to the surgery room for performing colostomy. The mother also described responsibility to protect her child's life when she saw her child in bed after the surgery: "When we, that is, members of my family, saw the baby after the surgery, my parents and my husband's parents began to argue about whose fault it was that the baby had anomalies. In the inside of it, I add "I could not afford to be involved in them," I thought that only I could protect my baby's life. There was also no time to worry about the disease. I was working to take care of my baby without considering anything else. "

The mother described having a period of depression after the child was discharged from the hospital: "I had so many worry that I could not talk about my worries."

By far, these changes in the mother's thoughts and feelings were categorized as defense to accept MCAs as it is. The following section describes the details.

When the child was 2 years old (at the first interview), the mother talked that she always had to it take care of her child's urine and facilities. Since the child did not have a bladder and urine was collected to the plastic bag, if it becomes fixed quantity, the mother had to throw away. If she had not noticed urine having

Questions regarding the support the mother have received:

1. What is the hardest part about raising a child with a congenital gastrointestinal tract malformation?

2. Who is the most helpful to you in taking care of your child?

3. Do your family, relatives, and doctors and your child's schoolteachers understand the difficulty you face in raising your child?

4. Do you talk with other mothers who have a child with the same disability? 
Table 1 Psychological measures of the mother of a child with MFAs.

\begin{tabular}{|c|c|c|c|c|}
\hline & $\begin{array}{c}\text { Results* } \\
\text { (Two years old) }\end{array}$ & Diagnosis & $\begin{array}{c}\text { Results* } \\
\text { (Five years old) }\end{array}$ & Diagnosis \\
\hline STAI-I & 67 & Very high & 68 & Very high \\
\hline STAI-II & 62 & Very high & 62 & Very high \\
\hline SDS & 56 & $\begin{array}{c}\text { Depression } \\
\text { level }\end{array}$ & 53 & $\begin{array}{l}\text { Depression } \\
\text { level }\end{array}$ \\
\hline
\end{tabular}

*The State-Trait Anxiety Inventory (STAI)-I, STAI-II and Self-rating Depression Scale (SDS) were administered to the mother when her child was two years old and again when her child was five years old

filled in a plastic bag and left it, there was a possibility that urine might flow backwards inside of child's body. It may have caused the serious infection for the child.

Since the child was building the artificial anus at first, the mother was performing the care every day. The anus is built at the hip after that, since the child's anus sphincter muscle was weak, facilities sometimes leaked to the buttocks. Because of facilities, the child's hips became that it tends to become sore red, and the care of the skin was required for them. In order to train child's anus sphincter muscle, disposal called "bougie" was also performed every day.

When the child was 5 years old, the mother described the impact of the child's MCAs as follows. "Now she grows up to talk with me, so pleasure of my life came out.

About the life of every day in case a child is 5 years old, the mother said that we had to take hospitalization procedure, when the child gives off heat. She said every time when child began to give off heat, she wondered "Is it becoming heavy sick?". She was always wishing that the child recovered immediately and it did not need to be sent to hospital. She said "I do not care in the case of the child caused sick like cold or otitis media that normal children can caused. But I don't want to hospitalize my child because of MCAs".

Even if there was no need of hospitalization for heat, the mother had to often take to the hospital for inspection of her child. Since the child was not able to walk, the mother used a wheelchair or held to move the child.

\section{Coping with the diagnosis}

Based on qualitative analysis of the data, the coping process could be divided into two stages. After the child was diagnosed with MCAs, the first stage concerned defense to accepting that the child had MCAs, critical disease in order to regulate its emotional impact. The second stage concerned controlling the situation, i.e., the extent to which the parents regained control of the situation and were able to remove the stressor of the possibility that their child might die. The mother made herself trust that his child was in a better state than other children. The father tended to look at only the healthy portion of their child, and tended to love only that.

When the child was two years old, the mother stated, "I saw children with esophageal atresia in the Pediatric Surgery Ward and they vomited food...As my child did not vomit, my child was better than the children with esophageal atresia". The doctor had already explained to her that the state of disability of the child was more serious than other diseases like esophageal atresia. The mother showed defense to take the disease as it is. The father regulated the amount of stress he could tolerate by using strategies that avoided the stressor. The mother reported, "My husband never took care of our child. He thinks that the mother should take care of a child. He also thinks that if he takes care of our baby, I will feel that I lose my value in the family. I do not feel that way at all."

When the child was five years old, the mother used confrontation rather than avoidance of the stress related to MCAs in her child in order to regulate its emotional impact. "I know that my child will require further surgery. Without surgery, my child will not be able to live any more...but I cannot decide-I want to postpone the admission of my child to the hospital, and spend time with her in my house."

\section{Influence of the disease on the mother}

A final theme that emerged was the influence of the child's disease on the mother. The child with MCAs in the present study does not have an older sibling. A potential younger sibling was sacrificed. The mother said that she became pregnant after the birth of her child with MCAs, but discontinued the pregnancy in order to care for her child with MCAs: "I was worried about who would take care of my child without me. I did not want to kill my baby, but I decided to have an abortion. "

That the mother had increased responsibilities was evident in this mother's statement. She had resigned from her job when the child was born and devoted herself to taking care of her child: "My workplace was the most favorite place for me. I felt fulfillment from my work. However, since I had a child with MCAs, I resigned from my job."

Mother rivalry or jealousy emerged in the family: "I am taking care of my child twenty-four hours a day and cannot separate from the child. I feel the most stress in this family. Members of my family, except me, are not serious. Everyone except I have free time". Since her husband, her parents and her husband's parents had a coping style of escape from the child with MCAs, only she was left to face her child's disease. The mother said, "My husband and my parents always say, 'I want to just love this baby, and not take care of the baby.' They are only helping me by playing with the baby or putting the baby in a bath."

Other mothers of children with a disease like imperforate anus or Hirschsprung's disease, who were in the same patient room during the hospitalization, provided support to this mother. "I think that the relationships with mothers, whose children are admitted in the same patient room as my child, are important. Especially in the case of my child who must be in the hospital for long periods of time, and who cannot leave the hospital for a short period of time. Since the mothers of children who were admitted in the same patient room taught me various things, I want to teach other mothers of a child with a disease during the next hospitalization of my child. I do not want to make to have had you teach from other mother into only my thing. I want to divide the knowledge acquired until now into the mother who came newly. 


\section{Discussion}

We interviewed a mother of a child with MCAs to discern her coping patterns toward the disease. We assessed the psychological state of the mother and found that the mother remained in a state of high anxiety and depression over a fiveyear period after the child's birth. Funakoshi [25] investigated the psychological state of the mothers of children who underwent pediatric surgery for the first time. Although the mothers of a child with imperforate anus or Hirschsprung's disease showed anxiety and depression, the psychological state of the mother became normal as the child grew older. However, unlike these mothers of a child who underwent pediatric surgery, the mother of the child with MCAs had a mental problem over a long period of time.

These findings on the impact of a child's disease on the child's mother were consistent with the findings of studies on parents whose children were diagnosed with various medical conditions [26-29]. These studies have surveyed parents of children with craniopharyngioma [26], congenital heart disease [27], spina bifida [28] and cancer [29]. The results showed that the mother experienced the following sequence of emotions: (1) Shock, (2) Absent-mindedness, (3) Feeling Responsibility, (4) Depression, (5) Defense; it was the same sequence of reactions as that of mothers of a child with other diseases found in previous studies. The period that extended from "defense" to "confrontation versus avoidance" in our mother was considered to be longer than that in mothers of children with other diseases.

A lack of acceptance or denial is commonly observed in parents when informed that their child has a serious congenital problem $[30,31]$. In the short term, denial provides protection from the emotional impact of adversity, but it becomes maladaptive when it inhibits the development of problem-solving behaviors and reduces the impetus to take effective action. The mother in our study indicated that she was unable to accept that her child had significant congenital problems "exactly" for at least two years. Rosenthal [26] reported that many parents of a child with MCAs said that the absence of a diagnosis had delayed their acceptance of the child's problems. In our case, the diagnosis of the child was made when the child was 3 days old, and the parents were informed of the diagnosis. However, since the child's disease is rare and complicated, it is thought that time was required for parents without specialized medical knowledge to understand the diagnosis. The design of our study did not allow us to quantify the degree to which the mother understood her child's disease, but it would be interesting to study whether parental acceptance is slower in the absence of understanding and if this delay in parental acceptance is harmful to her.

It is significant that the mother in the current study did not have the support of her husband, her parents nor her husband's parents. Since the coping style of her husband, her own parents and her husband's parents was to avoid the child with MCAs, the mother alone was left to face her child's disease. The mother received support only from other mothers of infants with diseases who were admitted in the same patient room. Saiki-Craighill [32] stated that since it is the mother's role to raise children in Japanese families, taking care of a child with a disease tends to become the mother's care alone.

Further research is needed to verify these reports on mothers (NOTE: What specifically needs to be verified or studied? I mean psychological research about the mother with MCAs.), but pediatricians and other providers should be aware of the need to provide support for mothers of children with congenital diseases. The importance of social support in adaptation to adverse events has been well documented [33] and the mother in this study felt frustrated in her attempts to locate appropriate support from her family. She reported that she joined support groups when she was in hospital with her child and got information about caring for her child from other parents with disabilities. Studies have found that the value of support groups is derived from the power of shared experience [34-37] and the parents of a child with a disease feel that the most appropriate source of peer support is from parents of children who have similar diagnoses. The mother in this study was active in peer groups that provided practical advice and emotional support, but her family did not provide one of the things she wanted most: help in taking care of her child.

Since the mother in this study was among a group of parents who were cooperative with our research in the Department of Pediatric Surgery, we cannot assume that these results can be generalized to all parents of children with MCAs. Also, Japanese people tend to consider children's diseases to be mothers' cause. If the child with congenital malformation is born, Japanese mother is in the tendency considered whether the problem was in meal or in family line. Further research is needed on how the level of acceptance of the child's disease by the child's parents is affected by factors such as the parents' knowledge of medicine, age and personal coping styles. There is ample evidence that culture plays an important role in the parental response to birth defects [38]. Socio-economic factors can have a major impact on the resources available to parents [39]. Therefore, it is important to study the parents of children with diseases from a wider range of backgrounds.

Pediatricians and other health care providers caring for children with unidentified birth defects usually know that the parents are eager to identify their child's condition. As a result, they may be highly motivated to arrange multiple evaluations aimed at providing the information the parents say they need to deal with their situation. It is important to remember that it is serious for parents to understand a diagnosis, and even if the parents understand the child's condition, it is likely that the parents will be present the defense to acceptance child's disease as it as.

Our findings from this study illustrate the complexity of parents' attitudes toward diagnostic information in their child. Medical providers have an important role to play in helping parents cope with their child's disease. 


\section{References}

1 Garro A (2004) Coping patterns in mothers/caregivers of children with chronic feeding problems. J Pediat Healthc 18: 138-144.

2 Board R, Ryan-Wegner N (2002) State of the science on parental stress and family functioning in pediatric intensive care units. Am J Crit Care 9: 106-122.

3 Powers SW, Bayars KC, Mitchell MJ, Patton SR, Standiford DA, et al. (2002) Parent report of mealtime behavior and parenting stress in young children with type 1 diabetes and in healthy control subjects. Diabetes Care 25: 313-318.

4 Sparacino PS, Tong EM, Messias DK, Foote D, Chesla CA (1997) The dilemmas of parents of adolescents and young adults with chronic heart disease. Heart and Lung 26: 187-195.

5 Speechley KN, Noh S (1992) Surviving childhood cancer, social support and parents' psychological adjustment. J Pediatr Psychol 17: 15-31.

6 Van Dongen-Melman JEWM, Pruyn JFA, De Groot A, Koot HM, Hählen K, et al. (1995) Late consequences for parents of children who survived cancer. J Pediatr Psychol 20: 567-586.

7 Danks D, Bodian M (1963) A genetic study of neonatal obstructive jaundice. Archives of Disease in Childhood 38: 378-390.

8 Bennet DE (1964) Problems in neonatal obstructive jaundice. Pediatrics 33: 735-748.

9 Silverberg M, Craig J, Gellis SS (1960) Problems in the diagnosis of biliary atresia. AMA J Dis Child 99: 574-584.

10 Amae S, Kamiyama T, Nio M, Yoshida S, Hayashi Y, et al. (2004) Biliary atresia with associated complicated anorectal and urogenital malformations. Pediatr Surg Int 20: 380-383.

11 Petersen C (2004) Surgery in biliary atresia-futile or futuristic? Eur J Pediatr Surg 14: 226-229.

12 Lazarus RS (1966) Psychological stress and the coping process. McGraw-Hill, New York.

13 Folkman S, Lazarus RS (1980) An analysis of coping in a middle-aged community sample. J Health Soc Behav 21: 219-239.

14 Giorgi AP (1984) Towards a new paradigm for psychology. In: Aanstoos CM (Edr.) Exploring the lived world: Readings in phenomenological psychology. Stud Soc Sci 23: 9-28.

15 Giorgi A (1986) Theoretical justification for the use of descriptions in psychological research. In: Ashworth PD, Giorgi A, De Koning AJJ (Edr) Qualitative research in psychology: Proceedings of the International Association for Qualitative Research in Social Science. Duquesne University Press, Pittsburgh.

16 Porter CJ, Potenza A (1983) Alternative methodologies for early childhood research. Adv Early Educ Day Care 3: 155-186.

17 Diseth TH, Bjornland K, Novik T, Emblem R (1997) Bowel function, mental health and psychosocial function in children with Hirschsprung's Disease. Arch Dis Child 76: 100-106.

18 Diseth, T.H. \& Emblem, R. (1996) Somatic function, mental health and psychosocial adjustment of adolescents with anorectal anomalies. J Pediatr Surg 33: 468-475.

19 Diseth TH, Emblem R, Solbraa IB, Vandvik IH (1994) A psychosocial follow-up of ten adolescents with low anorectal malformation. Acta Paediatr 83: 216-221.
20 Spielberger CD (1966) Theory and research on anxiety. In: Spielberger CD (Edr.) Anxiety and behavior. Academic Press, New York.

21 Zung WWK (1965) A self-rating depression scale. Arch Gen Psychiatry 12: $63-70$.

22 Nakazato K, Mizuguchi T (1982) How to use STAI. Sankyoubo Corp. Kyoto, Japan.

23 Fukuda K, Kobayashi S (1973) A study on a self-rating depression scale (author's transl). Seishin Shinkeigaku Zasshi 75: 673-679.

24. Chenitz WC, Swanson JM (1992) Grounded theory, Igaku-syoinn. Tokyo, Japan.

25 Funakosi S (2004) Psychosocial liaison-consultation for the children who have undergone repair of imperforate anus and hirschsprung's disease. J Pediatr Surg.

26 Jackson AC, Tsantefski M, Goodman H, Johnson B, Rosenfeld J (2003) The psychosocial impacts on families of low-incidence, complex conditions in children: The case of craniopharyngioma. Soc Work Health Care 38: 81-107.

27 Rempel GR, Cender LM, Lynam MJ, Sandor GG, Farquharson D (2004) Parent's perspectives on decision making after antenatal diagnosis of congenital heart disease. J Obstet Gynecol Neonatal Nurs 33: 64-70.

28 Zipitis CS, Paschalides C (2003) Caring for a child with spina bifida: Understanding the child and career. J Child Health Care 7: 101-112.

29 Kazak AE, Alderfer $M$, Rourke MT, Simms S, Streisand $R$, et al. (2004) Posttraumatic stress disorder (PTSD) and posttraumatic stress symptoms (PTSS) in families of adolescent childhood cancer survivors. J Pediatr Psychol 29: 211-219.

30 Canam C (1993) Common adaptive tasks facing parents of children with chronic conditions. J Adv Nurs 18: 46-53.

31 Lubinsky MS, Kahler SG, Speer IE, Hoyme HE, Kirillova IA, et al. (1994) von Voss-Cherstvoy syndrome: A variable perinatally lethal syndrome of multiple congenital anomalies. Am J Med Genet 52: 272-278.

32 Saiki-Craighill S (1997) The children's sentinels: Mothers and their relationships with health professionals in the context of Japanese health care. Soc Sci Med 44: 291-300.

33 Patterson JM, Garwick AW, Bennett FC, Blum RW (1997) Social support in families of children with chronic conditions: Supportive and no supportive behaviors. J Dev Behav Pediatr 18: 383-391.

34 Baley JE, Hancharik SM, Rivers A (1988) Observations of a support group for parents of children with severe bronchopulmonary dysplasia. J Dev Behav Pediatr 9: 19-24.

35 Santelli B, Turnbull A, Higgins C (1997) Parent to parent support and health care. Pediatr Nurs 23: 303-306.

36 Ainbinder JG, Blanchard LW, Singer GH, Sullivan ME, Powers LK, et al. (1998) A qualitative study of Parent to Parent support for parents of children with special needs. Consortium to evaluate Parent to Parent. J Pediatr Psychol 23: 99-109.

37 Law M, King S, Stewart D, King G (2001) The perceived effects of parent-led support groups for parents of children with disabilities. Phys Occup Ther Pediatr 21: 29-48.

38 Groce NE, Zola IK (1993) Multiculturalism, chronic illness and disability. Pediatrics 91: 1048-1055.

39 Thompson G (1996) Adaptation to chronic childhood illness. American psychological Assosiation, USA. 